\title{
Synthesis, Spectral Characterization and Solubility Studies Of Some Organotin Carboxylates
}

\author{
Yiase, Stephen Gbaoron ${ }^{1}$, Iorungwa, Moses Saviour ${ }^{2}$, Ogoh, Blessing ${ }^{3}$ \\ ${ }^{1}$ Department of Chemistry, Benue State University, Makurdi, 970001 - Nigeria \\ ${ }^{2,3}$ Inorganic/Physical Chemistry Research Group, Department of Chemistry, University of Agriculture, Makurdi - 970001 - Nigeria
}

\begin{abstract}
This study undertook the synthesis of four organotin compounds viz: dibutyltin stearate, dibutyltin salicylate, diphenyltin salicylate and triphenyltin acetyl salicylate using their salts and acids respectively. The melting range of the products was determined using a Griffin (MBF - 595 - $010 \mathrm{M}$ ) melting point apparatus. The characterization based on the tin content analysis showed a melting range of $60-62{ }^{\circ} \mathrm{C}$ and tin content of 14.62 for dibutyltin stearate, $78-80{ }^{\circ} \mathrm{C}$ and 23.63 for dibutyltin salicylate, $155-157^{\circ} \mathrm{C}$ and 21.27 for diphenyltin salicylate, $149-151{ }^{\circ} \mathrm{C}$ and 22.84 for triphenyltin acetyl salicylate. This showed that the increase in molecular weight of the organotin compounds increased their melting range. The spectral analysis was conducted using a Genesis series FTIR, Perkin Elmer UV-visible spectrophotometer (Lambda 3D).The products showed intense absorption bands at 1560 - $1601 \mathrm{~cm}^{-1}$ which has been assigned to $-\mathrm{CO}_{2}$ asymmetric stretching vibration. General features of the spectra support the claim for the synthesis of these compounds.
\end{abstract}

Keywords: Synthesis, Spectral Characterization, organotin carboxylates

\section{Introduction}

The industrial application of organotin compounds especially in the last few decades has grown considerably. As polymer stabilizer, dibutyltin laurates, has been used in the stabilization of some surface coatings. Dibutyltin myristate, palmitate and stearate have been found to be even better paint stabilizers [1]. Until recently, dibutyltin oxide and tributyltin acetate were used as antifouling agents in paints for ocean going vessels. Triphenyltin acetate is used in temperate countries for the control of Phytophthora infestans and Cercospora beticola, the causative agents for potato blight and the leaf spot ( in sugar beet) disease respectively (Holmes and Kaesz, 1961). Dibutyltin salicylate has been patented in the United States of America as a fungicide [2].

Organotin carboxylates comprise of an important class of tin compounds [3 - 6]. Certain derivatives have industrial applications in homogeneous catalysis and in the stabilization of polymers. Other use relate to agriculture where they have been employed as biocides against insects, mites, and fungi. In recent times, pharmaceutical properties of organotin carboxylates have been investigated, with particular reference to their antitumour properties [7]. Biocidal uses of organotin carboxylates have continued to attract attention [9], [10]. There is also interest in the structural chemistry of the compounds [11], [12], [13]. Organotin carboxylates are rapidly broken down to inorganic tin in the environment. The latter has been shown to be no - toxic and their degradation mechanisms involve the action of heat and light on these compounds. Studies [14] reported that, there is no accumulation of organic or inorganic tin in animals fed on foliage that were treated with organotin carboxylate fungicides. They observed $90 \%$ of ingested tin was excreted through feaces. The milk of such animals contained only $0.001 \mathrm{ppm}$ tin some of which was present in non - toxic form. Small quantity of tin appeared in the liver and kidney but these completely disappeared within a few weeks of cessation of the treatment.

For the purpose of this work, the organotin may be classified into the butyltin esters of aliphatic carboxylic acids, butyltin esters of aromatic carboxylic acids and the aliphatic and aromatic carboxylic esters of the phenyltin. Apart from the synthesis of the organotin, the melting/boiling points, tin analyses and infrared of the products were also determined.

\section{Materials and Methods}

\section{Chemicals and Reagents}

Acetone, dichloromethane, potassium hydroxide, hexane, distilled water dibutyltin chloride, triphenyltin hydroxide, Stearic acid, Salicylic acid, Acetylsalicylic acid and toluene. All the reagents used in this work were of analytical grade. The reagents were obtained from $\mathrm{BDH}$ chemical limited and Aldrich chemical limited England. All the solvents were dried and redistilled before use.

\section{SYNTHETIC STUDIES}

\section{Preparation of Dibutyltin Oxide}

Dibutyltin chloride $(40.0 \mathrm{~g}, 0.132 \mathrm{~mol})$ was dissolved in acetone $\left(200 \mathrm{~cm}^{3}\right)$ and transferred to a $500 \mathrm{~cm}^{3}$ separatory funnel. Potassium hydroxide (14.75g $0.264 \mathrm{~mol}$ ) was dissolved in $50 \mathrm{~cm}^{3}$ of distilled water and also transferred to the funnel. The mixture was vigorously shaken intermittently over a period of three hours and then left to stand for another three hours. A thick mass of colloidal precipitate of dibutyltin hydroxide was obtained. The suspension was transferred to a $500 \mathrm{~cm}^{3}$ conical flask and digested by heating under reflux for 30 minutes. This gave a granular precipitate. The precipitate was filtered using a sintered glass funnel and washed several times with distilled water to remove the potassium chloride formed in the process. The washing continued until the filtrate showed no 


\section{International Journal of Science and Research (IJSR) \\ ISSN (Online): 2319-7064 \\ Index Copernicus Value (2013): 6.14 | Impact Factor (2014): 5.611}

presence of chloride ions when tested with silver nitrate. The precipitate was washed with dry acetone to remove adsorbent water and then with hexane. It was dried in an oven at $105^{\circ} \mathrm{C}$ to a constant weight and weighed as dibutyltin oxide (32.44g, 96\% yield).

\section{Preparation of Dibutyltin Stearate $\left(\mathrm{Bu}_{2} \mathrm{SnSt}_{2}\right)$}

Dibutyltin stearate was obtained from the reaction of dibutyltin oxide $(3.0 \mathrm{~g}, 0.012 \mathrm{~mol})$ with Stearic acid $(1.44 \mathrm{~g}$, 0.02 mole) in dichloromethane $\left(50 \mathrm{~cm}^{3}\right)$ in a $100 \mathrm{~cm}^{3}$ Quick fit flask. The flask was fitted with a Dean-stark separator and a reflux condenser to effect dehydration of the mixture by azeotropic distillation in dichloromethane for 2 hours. The dichloromethane soluble dibutyltin stearate was recovered from the resulting solution by rotary evaporation under reduced pressure. The melting point of the product (4.1g, 97\%) was determined using Siwoloboff's method. The infrared spectra examination was done using a smear of the neat sample on a $\mathrm{NaCl}$ disc.

\section{Preparation of Dibutyltin Salicylate $\left(\mathrm{Bu}_{2} \mathrm{SnSa}_{2}\right)$}

Dibutyltin Salicylate was prepared using the same method described above for the synthesis of dibutyltin stearate from dibutyltin oxide and salicylic acid.

\section{Preparation of Silver Salicylate}

Silver oxide $(3.477 \mathrm{~g}, 0.015 \mathrm{~mol})$ was added to a solution of salicylic acid $(4.278 \mathrm{~g}, 0.031 \mathrm{~mol})$ in dry toluene $\left(150 \mathrm{~cm}^{3}\right)$. The mixture was stirred for two hours under aluminium foil cover. The solvent was then removed with a rotary evaporator. The water produced in the reaction was removed by azeotroic distillation with the solvent. The solid product of silver salicylate $(4.91 \mathrm{~g}, 98 \%)$ obtained was dried in vacuo.

\section{Preparation of diphenyltin Salicylate $\left(\mathrm{Ph}_{2} \mathrm{SnSa}_{2}\right)$}

Diphenyltin chloride $(3.252 \mathrm{~g}, 0.01 \mathrm{~mol})$ was dissolved in dry dichloromethane $(50.0 \mathrm{~cm} 3)$ in a $100 \mathrm{~cm} 3$ Quick fit flask. Silver Salicylate $(3.08 \mathrm{~g}, 0.013 \mathrm{~mol})$ was weighed and transferred to the flask. The flask was covered with aluminium foil and the mixture was stirred magnetically for 48 hours. The silver salt was removed by filtration using a sintered glass funnel. Evaporation of the resulting filtrate gave oil that crystallized on standing overnight. The product was re-crystallized from dry acetone after which the melting point and tin analysis were determined and the infra red spectra taken.

\section{Preparation of Triphenyltin Acetylsalicylate $\left(\mathrm{Ph}_{3} \mathrm{SnAs}\right)$}

Triphenyltin hydroxide $(5.22 \mathrm{~g}, 0.0142 \mathrm{~mol})$ was weighed and dissolved in dry acetone $\left(50 \mathrm{~cm}^{3}\right)$ in a $250 \mathrm{~cm}^{3}$ Quick fit flask. Then acetylsalicylic acid $(0.85 \mathrm{~g}, 0.0142 \mathrm{~mol})$ was weighed and transferred to the flask. The flask was shaken until the mixture homogenized. Molecular sieves $(5 \mathrm{~g}, \mathrm{BDH}$ type $2 \mathrm{~A}, 0.0625$ inch pellets) were added and the mixture was boiled under reflux for 3 hours and then filtered using a sintered glass funnel. A light pink oil was obtained when the filtrate was evaporated using a rotary evaporator. The oil was left to stand in vacuum. Gradually, pink crystals were formed from the oil. The crystals were first washed with cold acetone to remove the excess oil then re-crystallized from toluene. The melting point and tin analysis were determined and the infra red spectra of the saturated solution in trichloromethane were taken using a smear on a $\mathrm{NaCl}$ disc.

\section{Results and Discussion}

\section{Organotin Carboxylates Synthesis}

In preparation of dibutyltin oxide, the organotin reagent for dibutyltin fatty acid carboxylates synthesis employed a simple precipitation reaction as shown below.

$\mathrm{Bu}_{2} \mathrm{SnCl}_{2}+2 \mathrm{KOH} \longrightarrow \mathrm{Bu}_{2} \mathrm{Sn}(\mathrm{OH})_{2}+2 \mathrm{KCl} 1$

Complete precipitation was ensured by using a single-phase mixture of acetone and water as solvents. The product $\mathrm{Bu}_{2} \mathrm{Sn}(\mathrm{OH})_{2}$ easily eliminates water during drying according to the equation below.

$$
\mathrm{Bu}_{2} \mathrm{Sn}(\mathrm{OH})_{2} \stackrel{350^{\circ} \mathrm{C}}{\longrightarrow} \mathrm{Bu}_{2} \mathrm{SnO}+\mathrm{H}_{2} \mathrm{O}
$$

Refluxing the precipitate of $\mathrm{Bu}_{2} \mathrm{Sn}(\mathrm{OH})_{2}$, coagulated the extremely fine colloidal state initially formed thereby reducing the chances of contamination. Purity was further ensured by repeated washing of the precipitate with distilled water to remove all traces of $\mathrm{KCl}$ from the product as confirmed by test with silver nitrate. The products dibutyltin stearate, dibutyltin salicylate, diphenyltin salicylate and triphenyltin acetylsalicylate were all obtained as solid crystals.

Table 1: Melting points and Tin Analyses of Dibutyltin Stearate, Dibutyltin Salicylate, Diphenyltin Salicylate and Triphenyltin Acetyl Salicylate

\begin{tabular}{|c|c|c|c|c|}
\hline $\begin{array}{c}\mathrm{S} / \\
\mathrm{No}\end{array}$ & Carboxylates & $\begin{array}{c}\mathrm{M} / \mathrm{B} \text {. Pt } \\
\left({ }^{\circ} \mathrm{C}\right)\end{array}$ & \multicolumn{2}{|c|}{ Tin Analysis (\%) } \\
\hline & & & Found & Calculated \\
\hline 1 & $\left(\mathrm{C}_{4} \mathrm{H}_{9}\right)_{2} \mathrm{Sn}\left(\mathrm{OCOC}_{17} \mathrm{H}_{35}\right)_{2}$ & $60-62$ & 14.62 & 14.86 \\
\hline 2 & $\left(\mathrm{C}_{4} \mathrm{H}_{9}\right)_{2} \mathrm{Sn}\left(\mathrm{OCOC}_{6} \mathrm{H}_{4} \mathrm{OH}-\theta\right)_{2}$ & $78-80$ & 23.63 & 23.42 \\
\hline $\mathbf{3}$ & $\left(\mathrm{C}_{6} \mathrm{H}_{5}\right)_{2} \mathrm{Sn}\left(\mathrm{OCOC}_{6} \mathrm{H}_{4} \mathrm{OH}-\theta\right)_{2}$ & $\mathbf{1 5 5}-\mathbf{1 5 7}$ & $\mathbf{2 1 . 2 7}$ & $\mathbf{2 1 . 7 1}$ \\
\hline $\mathbf{4}$ & $\left(\mathrm{C}_{6} \mathrm{H}_{5}\right)_{3} \mathrm{SnOCOC} \mathrm{Sn}_{6} \mathrm{H}_{4} \mathrm{OCOCH}{ }_{3}-\theta$ & $\mathbf{1 4 9}-\mathbf{1 5 1}$ & $\mathbf{2 2 . 8 4}$ & $\mathbf{2 2 . 4 5}$ \\
\hline
\end{tabular}

Results of the melting points and the tin analyses of the prepared organotin carboxylates are presented in table 1 above. The trend in the melting points of the organotin carboxylates is as might be expected from molecular masses of the organotin esters. The method adopted for tin analyses was that reported by Farnsworth and Pekola [14]. This method has been reported to have a high level of precision and accuracy.

The difference between the observed and calculated values of tin expressed as a percentage of the latter are in the order of $3 \%$ or less. For the greater majority of compounds, this agreement is better than $1 \%$. The close agreement is taken to indicate the success of these preparations. 


\section{International Journal of Science and Research (IJSR) \\ ISSN (Online): 2319-7064 \\ Index Copernicus Value (2013): 6.14 | Impact Factor (2014): 5.611}

Table 2: Infrared Absorption Frequencies of the Dibutyltin Stearate, Dibutyltin Salicylate,Diphenyltin Salicylate and Triphenyltin Acetyl Salicylate.

\begin{tabular}{|c|c|c|c|c|c|c|c|c|c|}
\hline \multirow[t]{2}{*}{$\mathrm{S} / \mathrm{NO}$} & \multirow[t]{2}{*}{ ORGANOTIN CARBOXYLATE } & \multicolumn{8}{|c|}{ Infrared Absorption Frequencies $\left(\mathrm{cm}^{-1}\right)$} \\
\hline & & $\mathrm{O}-\mathrm{H}_{\text {str }}$ & C-H arom. & $-\mathrm{CO}_{2}^{-}$asy. & $-\mathrm{CH}_{3}$ asy def. & $\begin{array}{r}-\mathrm{CH}_{3} \text { asy } \\
-\mathrm{CO}_{2}^{-} \text {sym. }\end{array}$ & $\mathrm{M}-\mathrm{O}-\mathrm{C}$ & $\begin{array}{l}\mathrm{Sn}-\mathrm{Bu} \\
\mathrm{M}-\mathrm{Ph}\end{array}$ & $\mathrm{C}=\mathrm{C}_{\text {arom. }}$ \\
\hline 1 & $\left(\mathrm{C}_{4} \mathrm{H}_{9}\right)_{2} \mathrm{Sn}\left(\mathrm{OCOC}_{17} \mathrm{H}_{35}\right)_{2}$ & - & - & 1600 & 1464 & 1292 & 1032 & 670 & - \\
\hline 2 & $\left(\mathrm{C}_{4} \mathrm{H}_{9}\right)_{2} \mathrm{Sn}\left(\mathrm{OCOC}_{6} \mathrm{H}_{4} \mathrm{OH}-\theta\right)_{2}$ & 3164 & 3010 & 1630 & 1460 & 1310 & 1030 & 660 & $1583 / 1556$ \\
\hline 3 & $\left(\mathrm{C}_{6} \mathrm{H}_{5}\right)_{2} \mathrm{Sn}\left(\mathrm{OCOC}_{6} \mathrm{H}_{4} \mathrm{OH}-\theta\right)_{2}$ & 3237 & 3066 & 1659 & 1444 & 1348 & 980 & 654 & $1484 / 1611$ \\
\hline 4 & $\left(\mathrm{C}_{6} \mathrm{H}_{5}\right)_{3} \mathrm{SnOCOC}_{6} \mathrm{H}_{4} \mathrm{OCOCH}_{3}-\theta$ & - & 3066 & $1749 / 1563$ & 1411 & 1352 & 1011 & 656 & $1688 / 1620$ \\
\hline
\end{tabular}

\section{Infrared Spectral Data of the Organotin Carboxylates}

Organotin carboxylates essentially are esters. Unlike the atom in the alkyl esters however, the tin atom in these organotin esters is of low electronegativity. Thus it possesses a lower tendency to draw electrons from negative groups such as carboxylates. The Sn-O-C bond therefore confers a greater electron density on the oxygen atom compared to the $\mathrm{C}-\mathrm{O}-\mathrm{C}$ bond in alkyl esters. In addition, the tin atom possesses filled d-orbital. It is thus suitably placed to form pi bonds with the anti-bonding orbitals of the oxygen atom of appropriate symmetry. The overlap of these orbitals is sequel to back donation of electrons from the tin atom to the oxygen atom which would further enhance the electron density on the oxygen of the carboxylate moiety. Consequently, the organotin ester is more ionic than its alkyl counterparts.

An ionic carboxylate is resonance stabilized through the delocalization of charge within the carboxylate group. This lowers the double bond character of the carboxyl group and consequently its force constant. The frequency of absorption of the carboxylate vibrations is therefore expected at positions lower than is observed for alkyl esters $(\approx 1740 \mathrm{~cm}$ $1)$.

Bonire et al., [10] have shown that, the asymmetric $-\mathrm{CO}_{2^{-}}$ vibrations in organotin carboxylates occurs in the region of $1520-1580 \mathrm{~cm}^{-1}$. The corresponding symmetric vibrations are observed at $1390-1435 \mathrm{~cm}^{-1}$.
From the spectra of these compounds, an intense band appears in the region of $1560-1601 \mathrm{~cm}^{-1}$. This has been assigned to the $-\mathrm{CO}_{2-}$ asymmetric stretching vibration. In the spectra of the organotin esters of aromatic carboxylic acids, the frequency of this vibration is shifted slightly to lower frequencies due to the conjugation of the carboxyl group with the aromatic ring. The position of this band is that expected for the tin esters to which it has been assigned Other bands appear at $980-1080 \mathrm{~cm}^{-1}$ and $1420-1467 \mathrm{~cm}$ ${ }^{1}$. These have been assigned to Sn-O-C, Sn-butyl or Snphenyl and the -CO- asymmetric vibration and the $\mathrm{CH}_{3}$ asymmetric deformation respectively [10], [15].

The general features of the spectra support the claim for the synthesis of these compounds. For instance, both $-\mathrm{CO}_{2}$ stretch and the $\mathrm{C}=\mathrm{C}$ aromatic stretch are lower than is commonly found in the carboxylic acids or alcohol esters of the acids. This suggests bonding to a less electronegative atom such as tin. It is also observed that in the acetylsalicylate product, while the salicylate carboxyl group absorbs in the region of $1505 \mathrm{~cm}^{-1}$, the acetyl carboxyl group absorbs near $1750 \mathrm{~cm}^{-1}$ [15]. The lower absorption of the salicylate carboxyl group is consequent upon its conjugation with the aromatic ring and its attachment to the tin atom. The conjugation of the acetyl carboxyl oxygen with the ring raised its infrared absorption frequency.

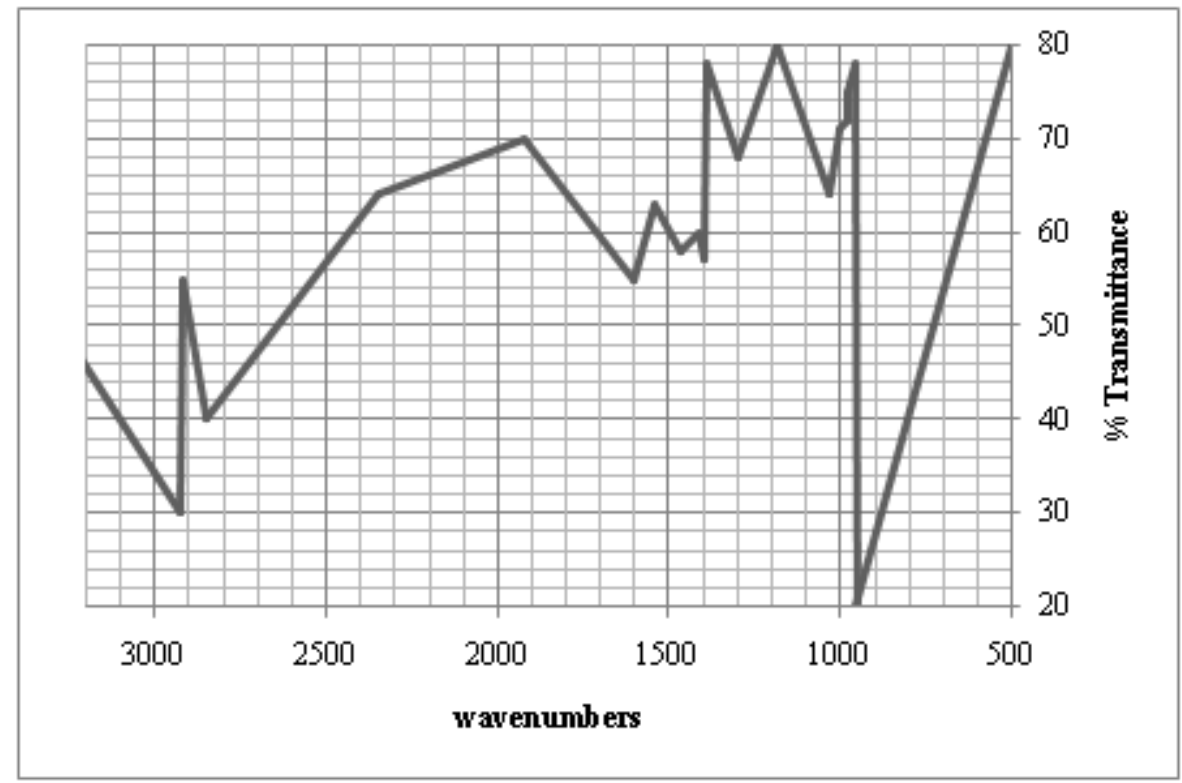

Figure 1: The IR Spectrum for dibutyltin stearate 
International Journal of Science and Research (IJSR)

ISSN (Online): 2319-7064

Index Copernicus Value (2013): 6.14 | Impact Factor (2014): 5.611

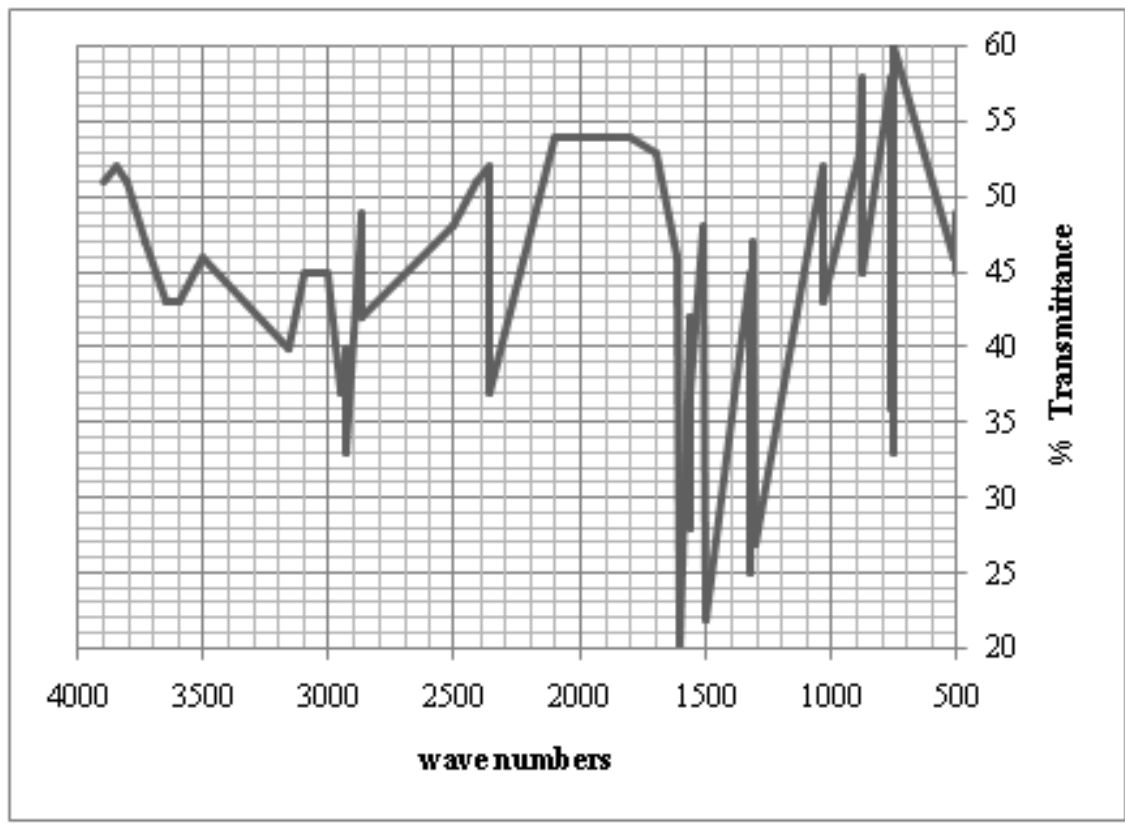

Figure 2: The IR Spectrum of dibutyltin salicylate

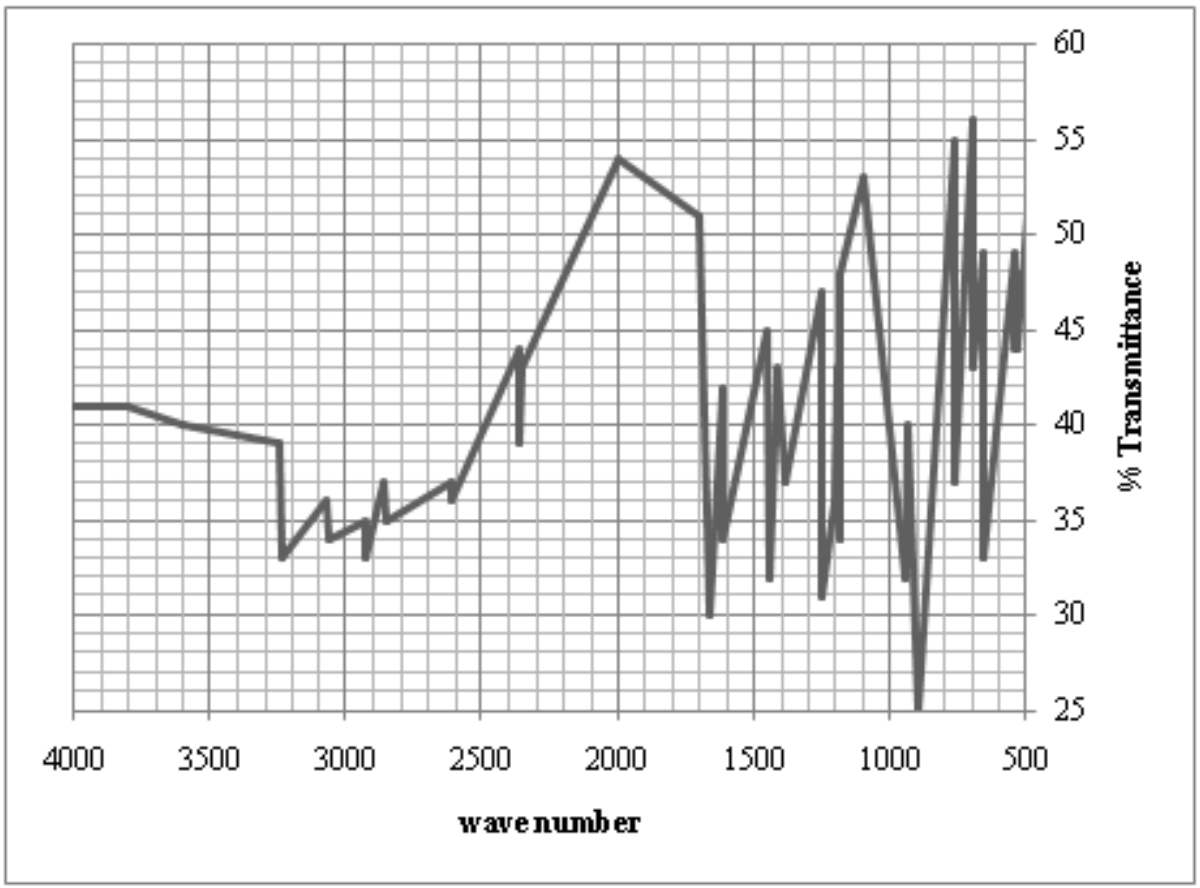

Figure 3: The IR spectrum of diphenyltin salicylate

Volume 4 Issue 12, December 2015

www.ijsr.net 


\section{International Journal of Science and Research (IJSR) \\ ISSN (Online): 2319-7064}

Index Copernicus Value (2013): 6.14 | Impact Factor (2014): 5.611

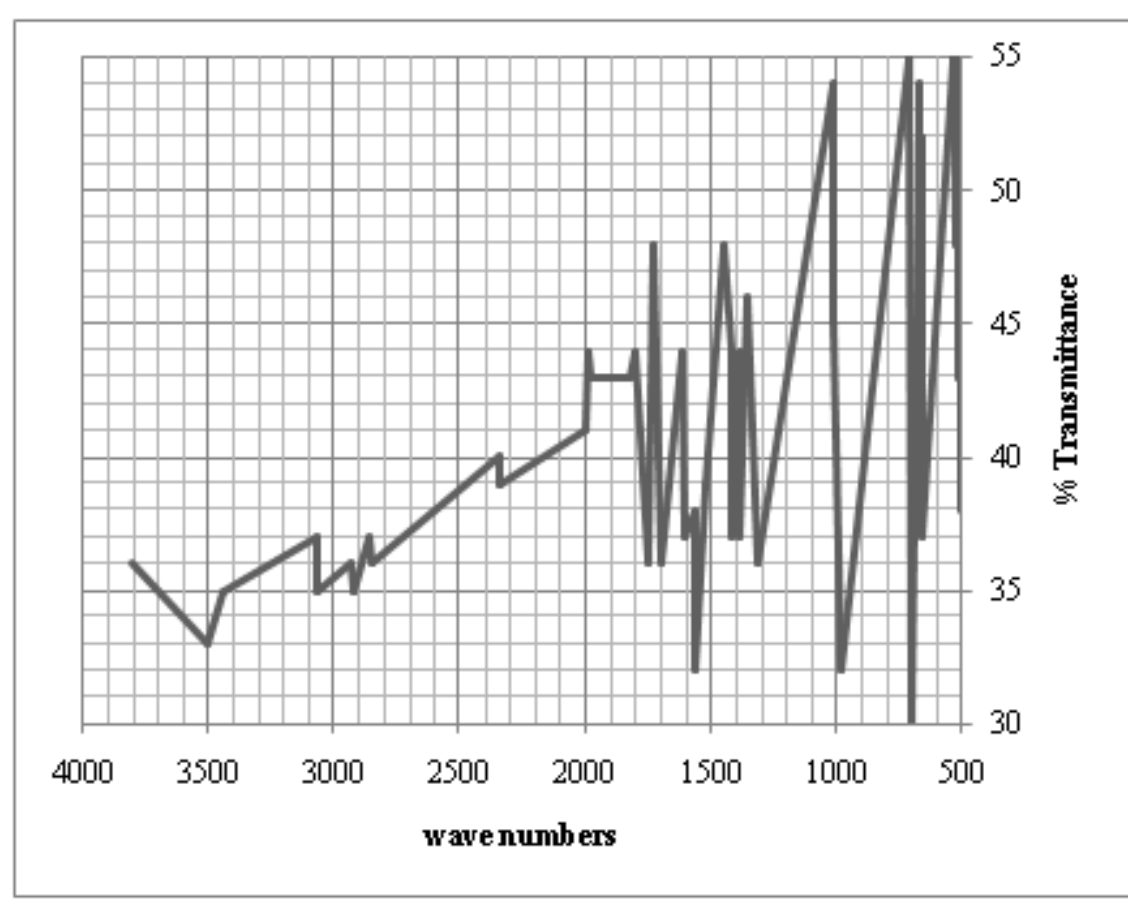

Figure 3: The IR Spectrum of triphenyltin acetylsalicylate

\section{Conclusion}

In the course of this research work it was established that the best solvent for the synthesis of organotin carboxylates from organotin chlorides and hydroxides is dichloromethane. In this solvent, silver carboxylates were found to be only marginally than the potassium equivalents. Tetra coordinate tin is found in all the organotin compounds from the mono - organotin to the tetra - organotin compounds.

\section{References}

[1] Turoti, M.O. (2001): Efficacy of Dibutyltin Dicarboxylates Alkyd Paint stabilizers. A Ph.D Thesis Submitted to the Postgraduate School A.B.U Zaria.

[2] Holmes,J. R. and Kaesz, H.D. (1961): Tin-proton SpinSpin Coupling in Methyltin Halides and Related Compounds. J. Am. Chem. Soc. 83:3903

[3] US Pat. (1966): Tin Dibutyldisalicylate Fungicides. Pat. No. 3284290

[4] Davies, A. G. and Smith, P. J., (1982): Comprehensive Organometallic Chemistry. John Wiley and Son, New York

[5] Evans, G. J. and Karpel, S. (1985): Organo Metallic Compound in Modern Technology. J. Organometallic Chemistry 16:1

[6] Blunden, S. J., Hobbs, L.A. and Smith, P. J. (1984): The Environmental Chemistry of Organotin Compounds: In Environmental chemistry, H.J.M Bowen (Specialist Periodical Reports), the Royal Society of Chemistry London, 640;49

[7] Omae, I. (1989): Organotin Chemistry. Journal of Organometallic Chemistry 21:15

[8] Gielen, M., Willem, R., Biesemans, M., Boualan, M., Elphaloufi, A., and De vos, D. (1992): Exceptionally High In-vitro Antitumor Activity of Triphenyltin Benzoates Including Salicylate against a Human
Mammary Tumor MCF-7 and Colon Carcinoma, W. Journal of Applied Organometallic Chemistry 6:287

[9] Eng, G., Whalem, D., Musingarimi, P., Tierney, J., and DeRosa, M. (1998): Fungicidal and Spectral Studies of Some Triphenyltin Compounds. Journal Applied Organometallic Chemistry 12:25

[10] Bonire,J.J., Ayoko, G.A., Olurinda, P.F.,Ehinmidu,J.O., Jalil, S.N. and Omachi, A.A. (1998): Synthesis and Antifungi Activity of Some Organotin (iv) Carboxylates. Metal-Base Drugs. 5(4):233.

[11]Cummin, R.A. and Dunn, P. (1964): Organotin Carboxylates. Austrialian Journal Chemistry, 17:185

[12] Bonire,J.J. (1985): Recations of the Pyridine Adduts of Organotin Halides: Synthesis of Spectral Properties of $\mathrm{Me}_{3} \mathrm{SnOCOCF}_{3}$ and $\mathrm{Me}_{2} \mathrm{Sn}\left(\mathrm{OCOCF}_{3}\right)_{2}$. Polyhedron 4 (10): 1707.

[13] Tiekink, E. R. T. (1991): Structural Chemistry of Organotin Carboxylates: A Review of the Chrystallographic Literature. Journal of Applied Organometallic Chemistry 5:1

[14] Farnsworth, M. and Pelola, J. (1959): Determination of Tin in Inorganic and Organic Compounds and Mixtures. Journal of Analytical Chemistry 31:40

[15] Yiase, S.G. (2003): Synthesis of some Organotin and Silicon Compounds and their Formulations as Antifungal Concentrates. PhD Thesis, Ahmadu Bello University Zaria - Nigeria 